\title{
Dose-response relationship between intergenerational contact frequency and depressive symptoms amongst elderly Chinese parents: a cross-sectional study
}

Yaofei Xie ${ }^{1 \dagger}$, Mengdi Ma ${ }^{2 \dagger}$, Wenwen $\mathrm{Wu}^{1}$, Yupeng Zhang ${ }^{1}$, Yuting Zhang ${ }^{1}$ and Xiaodong Tan ${ }^{1 *}$

\begin{abstract}
Background: Given the high prevalence of depressive symptoms amongst the elderly Chinese population and the significance of intergenerational contact in this demographic group, the purpose of this study was to examine the association and dose-response relationship between the frequency of intergenerational contact and depressive symptoms.

Methods: Data were obtained from the third wave of the China Health and Retirement Longitudinal Study. A total of 5791 participants at age 60 or older were included in this study. Depressive symptoms were defined by the 10item version of the Centre for Epidemiologic Studies Depression Scale. Intergenerational contact included in-person meeting and remote connecting, and they were analysed separately. Intergenerational contact frequency was classified into ten categories and then treated as a continuous variable for analysis. We performed univariate and multivariate logistic regressions to identify risk covariables. Restrictive cubic spline analysis was used to examine the dose-response relationship between intergenerational contact frequency and the outcome of depressive symptoms.

Results: Both the frequency of meeting and the frequency of connecting with children were independently associated with depressive symptoms in the elderly, and the odds ratios for depressive symptoms increased with decreasing frequencies $(P<0.01)$. There was a negative dose-response relationship between intergenerational contact frequency and depressive symptoms. The odds of depressive symptoms steadily decreased with increasing frequency of meeting with their children. Following an initial increase, the odds rapidly decreased as the frequency of connecting with children increased with an inflection point at once a monthly. Both associations were nonlinear $(P<0.001)$.
\end{abstract}

Conclusions: Our findings revealed a negative dose-response relationship between intergenerational contact frequency and depressive symptoms in the elderly Chinese population. Thus, future health interventions should consider cultural norms in shaping the mental well-being of Chinese elderly persons.

Keywords: China, Depressive symptoms, Dose-response, Elderly, Intergeneration

\footnotetext{
* Correspondence: 00300469@whu.edu.cn

†Yaofei Xie and Mengdi Ma contributed equally to this work.

'Wuhan University, No.115 of Donghu Road, Wuhan 430000, China

Full list of author information is available at the end of the article
}

(C) The Author(s). 2020 Open Access This article is licensed under a Creative Commons Attribution 4.0 International License, which permits use, sharing, adaptation, distribution and reproduction in any medium or format, as long as you give appropriate credit to the original author(s) and the source, provide a link to the Creative Commons licence, and indicate if changes were made. The images or other third party material in this article are included in the article's Creative Commons licence, unless indicated otherwise in a credit line to the material. If material is not included in the article's Creative Commons licence and your intended use is not permitted by statutory regulation or exceeds the permitted use, you will need to obtain permission directly from the copyright holder. To view a copy of this licence, visit http://creativecommons.org/licenses/by/4.0/ The Creative Commons Public Domain Dedication waiver (http://creativecommons.org/publicdomain/zero/1.0/) applies to the data made available in this article, unless otherwise stated in a credit line to the data. 


\section{Background}

Depressive disorders amongst the elderly population is a worldwide public health problem [1]. The Global Health Estimates reported by the World Health Organization (WHO) indicate that the prevalence of depressive disorders has peaked amongst the elderly [2]. In contrast to depressive disorders in younger populations, late life depression (major depressive disorders) is a risk factor for many chronic medical conditions [3, 4]. In addition, depression can result in significantly lower quality of life and increase mortality in the elderly population [5-7].

Depressive symptoms are the major manifestations of depressive disorders. The prevalence of depressive symptoms varies between regions and populations. A study of elderly Latinos in the United States reported a $25.5 \%$ prevalence of depressive symptoms [8]. Another study reported a $14.0 \%$ prevalence in elderly Americans of Chinese descent [9]. Two population-based studies conducted in Germany [10] and Greece [11] reported 28.7 and $32.3 \%$ prevalence of depressive symptoms amongst elderly, respectively. About $19.0 \%$ of elderly Koreans had depressive symptoms [12]. The 2008 Chinese Elderly Mental Health Survey revealed that over 39\% of the elderly participants self-reported depressive symptoms [13]. The 2011 China Health and Retirement Longitudinal Study (CHARLS) also reported that approximately 40\% of older adults had depressive symptoms [14]. China is facing a rapidly aging society; the proportion of elderly has grown from $13.3 \%$ [15] to $17.9 \%$ [16] of the population between 2010 and 2018. Thus, there is a corresponding growth in the number of older people displaying depressive symptoms.

Previous studies have found that contact frequency with offspring is inversely associated with depressive symptoms amongst older parents [17-19]. One explanation is that older parents expect support from their children, and when their adult children do not meet expectations, depressive symptoms may arise [20]. It has been suggested that intergenerational contact is a critical aspect of social support for the elderly [21], and the lack of which has been implicated in an increased risk of depressive symptoms [22]. Indeed, intergenerational contact provides an opportunity for companionship, sharing of interests and opinions, and for expression of emotions. For the elderly, these opportunities foster a sense of belonging to the family, and they also enable family members to offer help and care [23]. Children may provide a sense of meaning and order to life, and they may even be a source of self-esteem and prestige for the elderly [24].

Intergenerational contact is important for elderly Chinese people. Chinese Confucian cultures emphasises family and filial piety, and the practice of intergenerational contact is a part of filial piety. The absence of filial piety in the lives of Chinese elderly is connected with depressive symptoms [25-27]. One study in elderly Chinese-American also reported that those experiencing greater than expected filial piety had a lower risk of depressive symptoms [28].

More than ever, elderly Chinese people experience less contact with their adult children. According to the China Health and Retirement Report published by the CHARLS team in 2019, the number of elderly people not living in the same city as any of their children rose from 8 to $11 \%$ between 2011 and 2015. In the same period, there was also an increase from 19 to $24 \%$ in adult children living in different cities from their parents, and increasing distance between children and parents was associated with less intergenerational contact [29]. In addition, the proportion of 'empty nesters' (i.e., parents who do not live with their adult children) have increased remarkably and now includes nearly half of the elderly population in the country [30]. It is estimated that the proportion of empty-nester households could reach $90 \%$ by 2030 [31].

Several studies reported a high prevalence of depressive symptoms amongst empty nesters [32-34]. However, to our knowledge, no study has investigated the direct association between intergenerational contact frequency and depressive symptoms in the elderly Chinese population. To address this gap in knowledge, the present study in elderly Chinese participants aims to: (a) examine the association between intergenerational contact frequency and depressive symptoms, and (b) explore its dose-response relationship.

\section{Methods}

\section{Samples}

Data were obtained from the 2015 third wave survey data from the CHARLS study. CHARLS is an ongoing longitudinal study that collects demographic, social and economic data as well as the health status of nationally representative samples of middle-aged and elderly Chinese residents. CHARLS uses a four-stage sampling method. At the county and village levels, a probabilityproportional- to- size sampling method was used, and a total of 450 villages or communities were included. At the household and individual levels, the CHARLS researchers designed a software package named CHAR LS-Geographic Information System (CHARLS-GIS) to determine each sampling frame on the map. Furthermore, a sample of 80 households was randomly selected from a list of all households in each sampling frame. In every household sample, a family member over 45 years old was randomly selected as the main interviewee. Face-to-face interviews were then conducted by trained investigators to collect study data. The response rate was over $85 \%$ [35]. All the survey data are publicly available 
online. A total of 5791 participants were retained in the present study after removing the participants younger than 60 years and the participants with missing values on any of the main variables. The sample size was considered sufficient.

\section{Depressive symptoms}

Depressive symptoms were determined using the 10item version of the Centre for Epidemiologic Studies Depression Scale (CES-D-10) [36]. The Cronbach's alpha of the Chinese version of this scale was 0.813 [37].

The CES-D-10 contains three items addressing depressive affect, five addressing somatic symptoms, and two specifying positive affect. Each item has four options: option 1, "Rarely or none of the time (< 1 day)", option 2 , "Some or a little of the time $(1-2$ days)", option 3, "Occasionally or a moderate amount of the time (3-4 days)", option 4, "Most or all of the time (5 - 7 days)". Participants are asked to recall the frequency of specific feelings and behaviours during the past week and to choose the most appropriate response. Each item was rated from 0 to 3 , corresponding to the first through fourth options. Exception include 'Item 5' and 'Item 8', which are reverse-scored from 3 to 0 . The total score of the CES-D-10 scale ranged from 0 to 30 , and participants who scored $\geq 10$ points were considered to have significant depressive symptoms [38].

\section{Intergenerational contact}

Two intergenerational contact types were analysed: inperson "meetings" and remote "connections" made either by phone, text message, postal mail or email. The frequency was categorised into ten numbered items, $1=$ almost never, $2=$ less than once a year, $3=$ once a year, $4=$ once every 6 months, $5=$ once every 3 months, $6=$ once a month, $7=$ every 2 weeks, $8=$ once a week, $9=2-$ 3 times a week and $10=$ almost every day. The participants were allowed to select the number closest to the actual frequency. The contact frequency of all adult children was recorded and co-resident children were included under the category of "almost every day".

\section{Covariates}

We collected basic demographic characteristics including gender, age, marital status, education level, and residence that have been reported to be associated with depressive symptoms amongst the elderly Chinese population as control variables [39-41]. Previous studies reported that the presence of chronic disease was significantly related to depressive symptoms in the elderly [42, 43]. Conversely, old parents in poor physical health may stimulate increased contact with their children. So we used the variable of "number of chronic diseases suffered" to reduce the possibility of reverse causation. We analysed the intergenerational contact frequencies of all children in a family using the variable of "number of children" as a covariate to control for the effect of having multiple children.

\section{Statistical analysis}

We first conducted a descriptive analysis of all the study variables. Pearson chi-square tests and variance analyses were performed to assess differences in CES-D-10 scores and the prevalence of depressive symptoms in the subgroups. Next, univariate and multivariate logistic regression models were used to calculate the unadjusted and adjusted odds ratios (ORs) of the covariates to identify risk factors for depressive symptoms. Finally, we used restrictive cubic splines with four knots at the 25th, 50th, 75th, and 95th centiles to explore the dose-response relationship between intergenerational contact frequency and depressive symptoms. In the restrictive cubic spline analysis, the significant risk factors identified earlier were adjusted in the model. The frequency of "meetings" and the frequency of "connections" were mutually adjusted. A likelihood ratio was used to test for non-linearity [44, 45]. Missing values were accounted by using regression interpolation. Statistical significance was set to $P<0.05$, and all $P$-values were two-sided.

\section{Results}

\section{Participants and depressive symptoms}

Table 1 displays the demographic characteristics, CESD-10 scores, and the prevalence of depressive symptoms. Among the 5791 participants, males accounted for about $56 \%$, the average age was 69 years old, and over $60 \%$ were from 60 to 69 years old. Nearly two-thirds of the participants were living with their spouse, and more than $70 \%$ lived in villages. Uneducated participants accounted for about $30 \%$ of the sample, and nearly half of them completed education no further than elementary-level. Nearly $60 \%$ of their household consumption expenditures per capita fell within 0-2000 RMB. More than $80 \%$ of participants reported that they were diagnosed with at least one type of chronic disease. Over $90 \%$ of participants had more than one child.

In terms of intergeneration contact frequency, participants that met with their children either at least once a week or 1-2 times a month accounted for approximately $30 \%$ of the sample each. Over a quarter of participants met with their children 1-2 times every 6 months, and about $12 \%$ reported a frequency of $\leq 1$ time per year. The participants who connected with their children either $\geq 2$ times or 1 time a week accounted for approximately one-third of the sample each. About 15\% of participants connected with their children 1-2 times a month, while others reported the frequency at $\leq 1$ time every 3 months. 
Table 1 Participant characteristics by CES-D-10 scores and depressive symptoms

\begin{tabular}{|c|c|c|c|c|c|}
\hline Variables & $\mathrm{N}(\%)$ & $\begin{array}{l}\text { CES-D-10 scores } \\
(\text { Mean } \pm \text { SD) }\end{array}$ & $F$ & $\begin{array}{l}\text { Depressive symptoms } \\
\text { (N / prevalence \%) }\end{array}$ & $x^{2}$ \\
\hline Gender & & & $209.159^{* * *}$ & & $157.471^{* * *}$ \\
\hline Male & $3216(55.53)$ & $7.72 \pm 6.14$ & & $977(30.38)$ & \\
\hline Female & $2575(44.47)$ & $10.23 \pm 7.05$ & & $1196(46.45)$ & \\
\hline Age (years old) & & & 1.138 & & 2.646 \\
\hline $60-69$ & $3504(60.51)$ & $8.74 \pm 6.70$ & & $1318(37.61)$ & \\
\hline $70-79$ & $1791(30.93)$ & $9.03 \pm 6.70$ & & $685(38.25)$ & \\
\hline$\geq 80$ & $496(8.57)$ & $8.73 \pm 6.48$ & & $170(34.27)$ & \\
\hline Marriage status & & & $64.053^{* * *}$ & & $83.448^{* * *}$ \\
\hline Living with spouse present & $3788(65.41)$ & $8.12 \pm 6.36$ & & $1262(33.32)$ & \\
\hline Married but not living with spouse temporarily & $190(3.28)$ & $9.42 \pm 6.48$ & & $81(42.63)$ & \\
\hline Divorced / Widowed / Never married & $1813(31.31)$ & $10.25 \pm 7.11$ & & $830(48.78)$ & \\
\hline Residence & & & $52.735^{* * *}$ & & $102.656^{* * *}$ \\
\hline Main city zone & $916(15.82)$ & $6.62 \pm 5.82$ & & $226(24.67)$ & \\
\hline Town area & $540(9.32)$ & $7.80 \pm 6.38$ & & 167 (30.93) & \\
\hline Township & $255(4.40)$ & $8.42 \pm 6.28$ & & $88(34.51)$ & \\
\hline Village & $4080(70.45)$ & $9.49 \pm 6.80$ & & $1692(41.47)$ & \\
\hline Education level & & & $75.525^{* * *}$ & & $190.701^{* * *}$ \\
\hline Illiterate & $1705(29.44)$ & $10.57 \pm 7.18$ & & $812(47.62)$ & \\
\hline Elementary school or below & $2706(46.73)$ & $8.91 \pm 6.56$ & & $1030(38.06)$ & \\
\hline Middle school & $851(14.70)$ & $6.92 \pm 5.75$ & & $229(26.91)$ & \\
\hline High school or Vocational school & $410(7.08)$ & $6.02 \pm 5.44$ & & $81(19.76)$ & \\
\hline Bachelor's degree / Associate degree or greater & $119(2.05)$ & $5.53 \pm 4.65$ & & $21(17.65)$ & \\
\hline Household per capita consumptions expenditure last year ${ }^{a}$ & & & 0.936 & & 3.474 \\
\hline$\leq 2000 \mathrm{RMB} / 286.69$ US\$ / $255.90 €$ & $3302(57.02)$ & $8.87 \pm 6.71$ & & $1233(37.34)$ & \\
\hline$\sim 5000$ RMB / 716.72 US\$ / $639.75 €$ & $1233(21.29)$ & $9.00 \pm 6.47$ & & $487(39.50)$ & \\
\hline$\sim 10,000 \mathrm{RMB} / 1433.44$ US\$ / $1279.51 €$ & $630(10.88)$ & $8.57 \pm 6.98$ & & $223(35.40)$ & \\
\hline$>10,000 \mathrm{RMB} / 1433.44$ US\$ / $1279.51 €$ & $626(10.81)$ & $8.58 \pm 6.62$ & & $230(36.74)$ & \\
\hline Number of chronic diseases suffered ${ }^{b}$ & & & $135.991^{* * *}$ & & $246.78^{* * *}$ \\
\hline None & $1103(19.05)$ & $6.57 \pm 5.52$ & & $264(23.93)$ & \\
\hline One & $1452(25.07)$ & $7.83 \pm 6.22$ & & $468(32.23)$ & \\
\hline Two & $1309(22.60)$ & $8.52 \pm 6.37$ & & $466(35.60)$ & \\
\hline Three or more & $1927(33.28)$ & $11.09 \pm 7.15$ & & $975(50.60)$ & \\
\hline Number of children & & & $25.595^{* * *}$ & & $11.394^{* *}$ \\
\hline One & $498(8.60)$ & $7.39 \pm 6.20$ & & $152(30.52)$ & \\
\hline Two or more & $5293(91.40)$ & $8.97 \pm 6.71$ & & $2021(38.18)$ & \\
\hline Frequency of meeting with children & & & $35.732^{* * *}$ & & $79.056^{* * *}$ \\
\hline At least once a week & $1725(29.79)$ & $7.70 \pm 6.37$ & & $524(30.38)$ & \\
\hline $1-2$ times a month & $1793(30.96)$ & $8.66 \pm 6.44$ & & $653(36.42)$ & \\
\hline $1-2$ times every 6 months & $1533(26.47)$ & $9.64 \pm 6.82$ & & $656(42.79)$ & \\
\hline Once a year or less & $740(12.78)$ & $10.22 \pm 7.17$ & & $340(45.95)$ & \\
\hline Frequency of connecting with children & & & $28.873^{* * *}$ & & $60.018^{* * *}$ \\
\hline At least twice a week & $1985(34.28)$ & $7.80 \pm 6.32$ & & $611(30.78)$ & \\
\hline Once a week & $1948(33.64)$ & $8.99 \pm 6.61$ & & $782(40.14)$ & \\
\hline
\end{tabular}


Table 1 Participant characteristics by CES-D-10 scores and depressive symptoms (Continued)

\begin{tabular}{llll}
\hline Variables & N (\%) & $\begin{array}{l}\text { CES-D-10 scores } \\
\text { (Mean } \pm \text { SD) }\end{array}$ & $\begin{array}{l}\text { Depressive symptoms } x^{2} \\
\text { (N / prevalence \%) }\end{array}$ \\
\hline 1-2 times a month & $900(15.54)$ & $9.85 \pm 7.01$ & $375(41.67)$ \\
Once every 3 months or less & $958(16.54)$ & $9.70 \pm 6.93$ & $405(42.28)$ \\
Total & $5791(100.00)$ & $8.83 \pm 6.68$ & $2173(37.52)$ \\
\hline
\end{tabular}

${ }^{*} P<0.05 ;{ }^{* * *} P<0.01 ;{ }^{* * * *} P<0.001$

${ }^{a}$ The exchange rates of RMB against US dollar and euro were the rates on January 1, 2020. The absolute poverty line of Chinese population in 2019 was 2300 RMB annual per capita disposable income

${ }^{\mathrm{b}} \mathrm{A}$ total of 14 types of chronic diseases were asked: 1. Hypertension; 2. Dyslipidemia (elevation of low density lipoprotein, triglycerides (TGs), and total cholesterol, or a low high density lipoprotein level); 3. Diabetes or high blood sugar; 4. Cancer or malignant tumor (excluding minor skin cancers); 5. Chronic lung diseases, such as chronic bronchitis, emphysema (excluding tumors, or cancer); 6. Liver disease (except fatty liver, tumors, and cancer); 7. Heart attack, coronary heart disease, angina, congestive heart failure, or other heart problems; 8. Stroke; 9. Kidney disease (except for tumor or cancer); 10. Stomach or other digestive disease (except for tumor or cancer); 11. Emotional, nervous, or psychiatric problems; 12. Memory-related disease; 13. Arthritis or rheumatism; 14. Asthma

The mean CES-D-10 score of all the participants was $8.83 \pm 6.68$. Using $\geq 10$ as the cut-off score, depressive symptoms were identified in $37.52 \%$ of the participants. The variance analysis and chi-square test results revealed that gender, marital status, residence, education level, number of chronic diseases, number of children, frequency of meeting with children, and frequency of connecting with children were each associated with differences in CES-D-10 scores and in the prevalence of depressive symptoms $(P<0.001)$.

\section{Depressive symptoms and associated factors}

Table 2 presents the results of the logistic regression models for the associated factors of depressive symptoms. The unadjusted ORs for significant variables were calculated. We tested for collinearity on all independent variables using tolerance and variance inflation factors (VIFs) before multivariate analyses. All values for tolerance were over 0.1 and all VIFs were less than 10.0, therefore, there was no collinearity among independent variables.

Adjusted regression analysis showed that depressive symptoms were more likely to be identified in women (OR: 1.69, 95\% CI: 1.49-1.92); those who were divorced, widowed, never married, or cohabitated (OR: 1.29, 95\% CI: 1.13-1.47); those who lived in villages (OR: 1.78, 95\% CI: 1.47-2.14); those with a low education level; those who met up with their children less than once weekly; and those who connected with their children less than twice weekly. The odds of depressive symptoms increased with an increasing number of chronic diseases: 44,74 , and $234 \%$ for one, two, and three or more conditions, respectively. There was no significant association between the number of children and depressive symptoms.

\section{Depressive symptoms and intergenerational contact}

Multiple logistic regression results demonstrated that intergenerational contacts were independently associated with depressive symptoms amongst the elderly Chinese population. Figure 1 illustrates the changes in
CES-D-10 scores and prevalence of depressive symptoms in conjunction with (a) meeting with children in-person and (b) connecting with children remotely through different methods. Overall, it shows that lower CES-D-10 scores and fewer depressive symptoms tend to trend with increasing frequency of intergenerational contact.

Figure 2 shows the dose-response relationship between depressive symptoms and intergenerational contact frequency resulting from restricted cubic splines analyses. The analyses were adjusted for the factors associated with depressive symptoms in multivariable logistic regression. Both models were nonlinear $(P<0.001$ for the non-linearity test).

Figure 2(a )illustrates the steadily decreasing ORs for depressive symptoms with an increasing frequency of meeting with children. Remarkably, the odds of depressive symptoms show a significant inverse association with contact frequency when it falls below once monthly (Frequency of meeting with children $=6$ ). Meanwhile, Fig. 2(b) shows the ORs for depressive symptoms increased slightly followed by a sharp decrease as the frequency of connecting with children increases. The inflection point for the changes in ORs occurs at oncemonthly connections. (Frequency of connecting with children $=6$ ).

\section{Discussion}

The increasing social-structural constraints on resources and time have reduced intergenerational contact between the elderly Chinese population and their adult children. Considering China's traditional family culture and the special importance of intergenerational contact for this group, the present study investigated the relationship between intergenerational contact and depressive symptoms.

We found overall prevalence of depressive symptoms in the participants was $37.5 \%$ as defined by a CES-D- 10 score of $\geq 10$, which is higher than the prevalence reported in the elderly Japanese population of $11.5 \%$. That study defined depressive symptoms using the Geriatric 
Table 2 Multivariable logistic regression of factors associated with depressive symptoms

\begin{tabular}{|c|c|c|c|c|}
\hline Independent Variable & $\begin{array}{l}\text { Unadjusted OR } \\
(95 \% \mathrm{Cl})\end{array}$ & $P$ & $\begin{array}{l}\text { Adjusted OR }{ }^{\mathrm{a}} \\
(95 \% \mathrm{Cl})\end{array}$ & $P$ \\
\hline \multicolumn{5}{|l|}{ Gender (Male as reference) } \\
\hline Female & $1.99(1.78-2.21)$ & $<0.001$ & $1.69(1.49-1.92)$ & $<0.001$ \\
\hline \multicolumn{5}{|c|}{ Marriage Status (Living with spouse present as reference) } \\
\hline Married but not living with spouse temporarily & $1.49(1.11-2.00)$ & 0.008 & $1.36(1.00-1.85)$ & 0.054 \\
\hline Divorced / Widowed / Never married / Cohabitated & $1.69(1.51-1.89)$ & $<0.001$ & $1.29(1.13-1.47)$ & $<0.001$ \\
\hline \multicolumn{5}{|l|}{ Residence (Main city zone as reference) } \\
\hline Town area & $1.37(1.08-1.73)$ & 0.010 & $1.20(0.93-1.54)$ & 0.155 \\
\hline Township & $1.61(1.19-2.17)$ & 0.002 & $1.35(0.98-1.86)$ & 0.066 \\
\hline Village & $2.16(1.84-2.55)$ & $<0.001$ & $1.78(1.47-2.14)$ & $<0.001$ \\
\hline \multicolumn{5}{|l|}{ Education level (Illiterate as reference) } \\
\hline Elementary school or below & $0.68(0.60-0.76)$ & $<0.001$ & $0.88(0.76-1.01)$ & 0.060 \\
\hline Middle school & $0.40(0.34-0.48)$ & $<0.001$ & $0.64(0.52-0.78)$ & $<0.001$ \\
\hline High school or Vocational school & $0.27(0.24-0.35)$ & $<0.001$ & $0.46(0.35-0.63)$ & $<0.001$ \\
\hline Bachelor's degree / Associate degree or greater & $0.24(0.15-0.38)$ & $<0.001$ & $0.48(0.29-0.80)$ & 0.005 \\
\hline \multicolumn{5}{|c|}{ Number of chronic diseases suffered (None as reference) } \\
\hline One & $1.51(1.27-1.80)$ & $<0.001$ & $1.44(1.20-1.73)$ & $<0.001$ \\
\hline Two & $1.76(1.47-2.10)$ & $<0.001$ & $1.74(1.44-2.09)$ & $<0.001$ \\
\hline Three or more & $3.25(2.76-3.84)$ & $<0.001$ & $3.34(2.81-3.96)$ & $<0.001$ \\
\hline \multicolumn{5}{|l|}{ Number of children (One as reference) } \\
\hline Two or more & $1.41(1.15-1.71)$ & 0.001 & $0.96(0.77-1.19)$ & 0.702 \\
\hline \multicolumn{5}{|c|}{ Frequency of meeting with children (Over once a week as reference) } \\
\hline $1-2$ times a month & $1.31(1.14-1.51)$ & $<0.001$ & $1.20(1.04-1.40)$ & 0.016 \\
\hline $1-2$ times every 6 months & $1.71(1.48-1.98)$ & $<0.001$ & $1.49(1.28-1.74)$ & $<0.001$ \\
\hline Once a year or less & $1.95(1.63-2.33)$ & $<0.001$ & $1.68(1.39-2.03)$ & $<0.001$ \\
\hline \multicolumn{5}{|c|}{ Frequency of connecting with children (At least twice a week as reference) } \\
\hline Once a week & $1.51(1.32-1.72)$ & $<0.001$ & $1.28(1.07-1.52)$ & 0.006 \\
\hline $1-2$ times a month & $1.61(1.36-1.89)$ & $<0.001$ & $1.32(1.11-1.58)$ & 0.002 \\
\hline Once every 3 months or less & $1.65(1.40-1.93)$ & $<0.001$ & $1.34(1.17-1.55)$ & $<0.001$ \\
\hline
\end{tabular}

a adjusted for gender, marriage status, residence, education level, number of chronic diseases suffered, number of children, frequency of meeting with children, frequency of connecting with children.

$O R$ odds ratio and $\mathrm{Cl}$ confidence intervals

Depression Scale (GDS) with a cut-off score of $\geq 6$ [46]. Our result is also higher than the prevalence of $31.5 \%$ reported in elderly Europeans; the results there were measured using the EURO-D scale with a cut-off score of $\geq 4$ [47]. By contrast, the prevalence for institutionalised elderly persons in Brazil was $45.8 \%$ [48] and it was $60.6 \%$ in elderly Nepalese [49]. Depressive symptoms in these studies were also defined by the GDS with a cutoff score of $\geq 6$. The differences in these findings may be attributed to the economic and cultural differences amongst different regions.

Depressive symptoms amongst the elderly Chinese are associated with low levels of education, unmarried status, and location setting of residence, which are consistent with several previous studies $[39,40,50]$.
Amongst the elderly Chinese, intergenerational contact frequency is independently and inversely associated with depressive symptoms; it exhibits a negative dose-response relationship with the odds of depressive symptoms. For in-person interactions, the ORs for depressive symptoms did not increase significantly with a decrease of frequency of interaction until they reached a frequency of $\leq 1$ time monthly compared with those who have almost daily contact. The results suggest that children should meet up with their older parents at least once a month to possibly prevent them from developing depressive symptoms. This result is similar to a study in the U.S. that reported that the frequency of in-person interactions with children was inversely associated with the development of depressive symptoms in older 

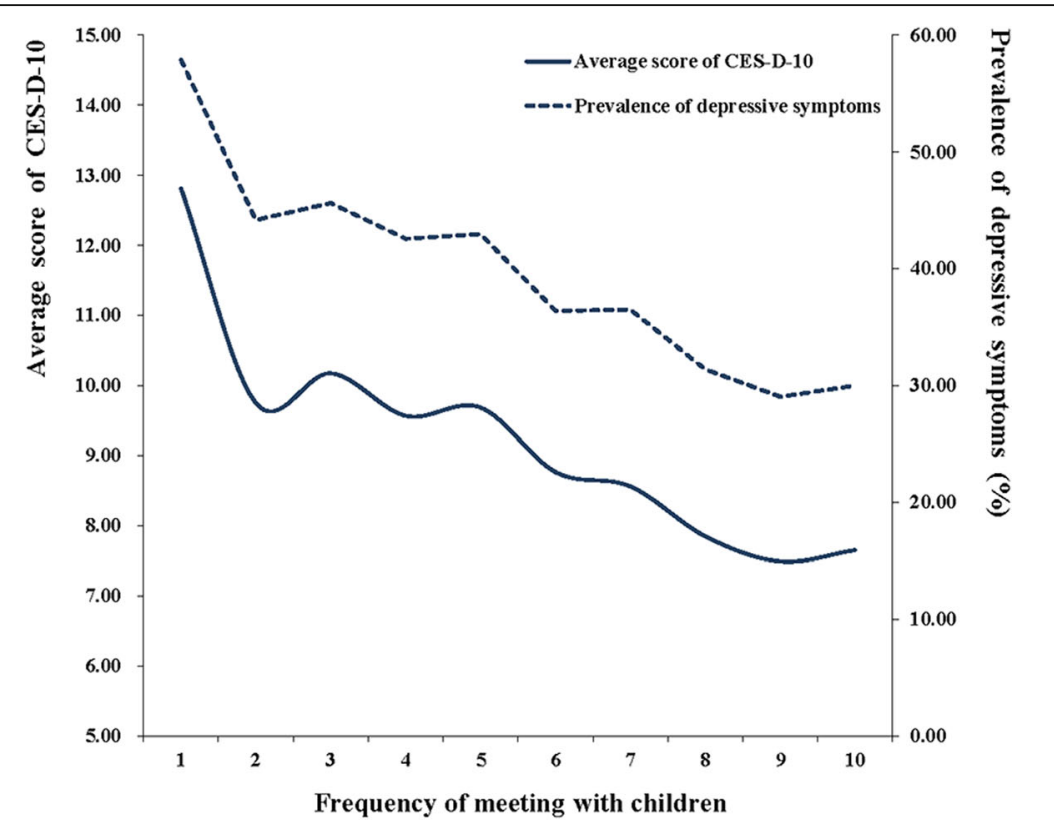

(a)

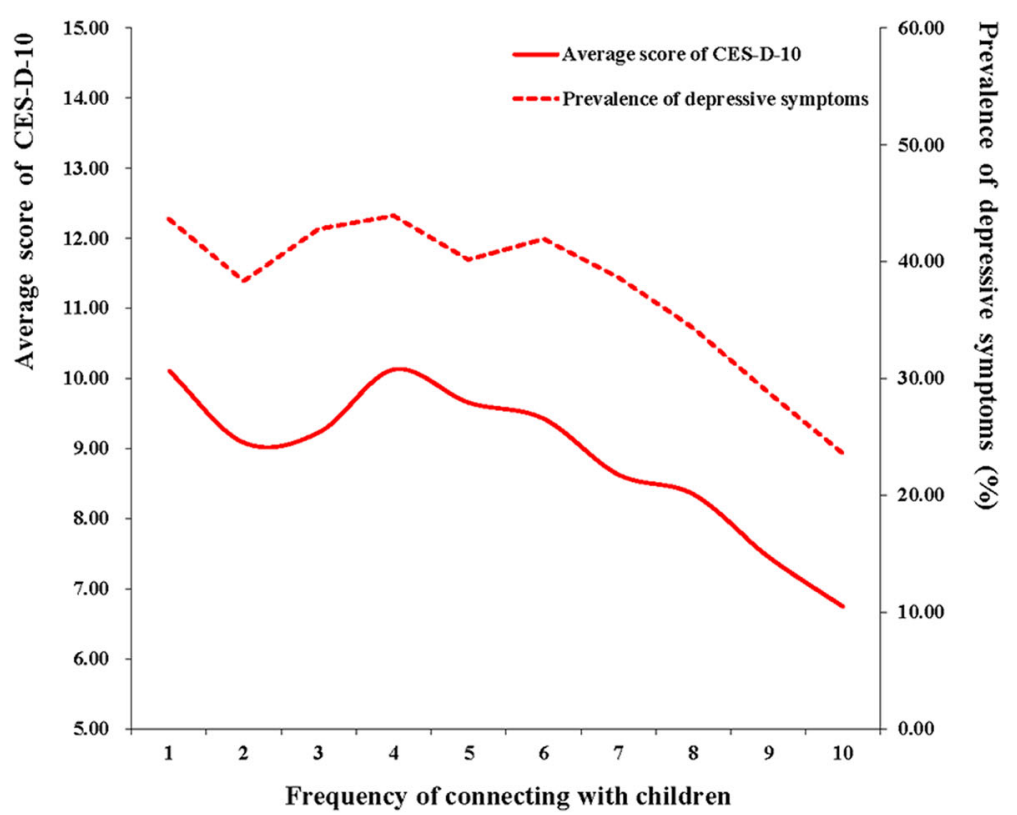

(b)

Fig. 1 Changes in CES-D-10 scores and in the prevalence of depressive symptoms relative to intergenerational contact frequency. Frequency: $1=$ almost never, $2=$ less than once a year, $3=$ once a year, $4=$ once every 6 months, $5=$ once every 3 months, $6=$ once a month, $7=$ every 2 weeks, $8=$ once a week, $9=2-3$ times a week and $10=$ almost every day

parents [51]. For contact by telephone, postal mail, or email, relative to connecting almost everyday, the ORs for depressive symptoms rapidly increased with a decrease in the frequency of connection. They reached an inflection point where connections were made once a month, whereby the ORs decreased slightly with a decrease in contact frequency. We suggest that other forms of contact are more easily accessible, therefore parents expect a greater frequency of interaction with their children, and they develop depressive feelings more easily when there is a minor decrease in contact frequency. But when the frequency drops to once monthly, their depressive feelings reach a stable level but do not get worse. During the coronavirus disease 2019 (COVID-19) pandemic, quarantines were implemented to prevent disease transmission, but concurrently, they had a 


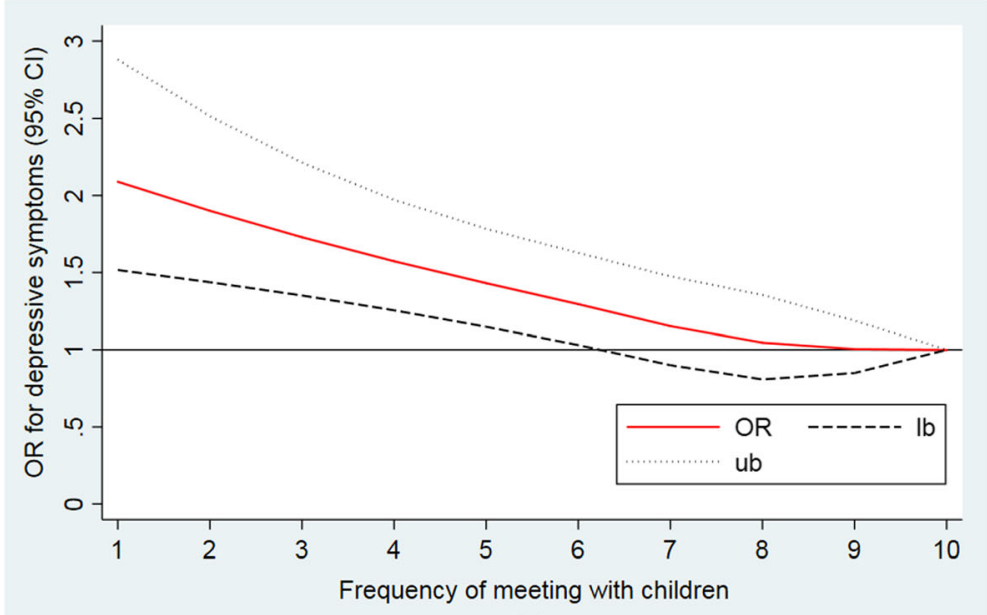

(a)

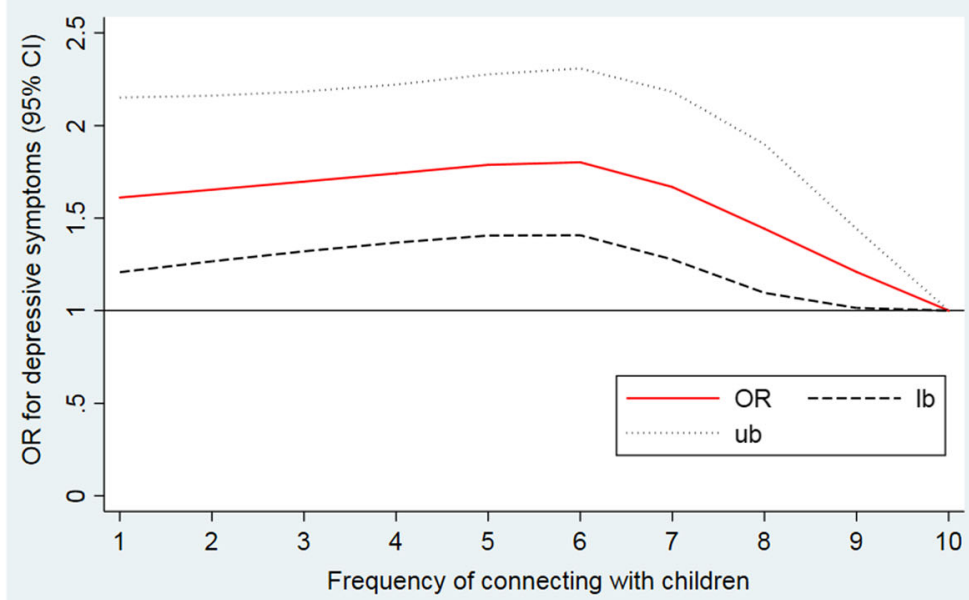

(b)

Fig. 2 Dose-response association between intergenerational contact frequency and the odds for depressive symptoms. Frequency: $1=$ almost never, $2=$ less than once a year, $3=$ once a year, $4=$ once every 6 months, $5=$ once every 3 months, $6=$ once a month, $7=$ every 2 weeks, $8=$ once a week, $9=2-3$ times a week and $10=$ almost every day. OR: odd raio; lb.: lower limit; ub: upper limit

negative psychological impact [52-54]. Our findings suggest that children should keep close connections with their older parents during periods of quarantine, which may help reduce the risk of depressive symptoms.

The associations of depressive symptoms and intergenerational contact frequency might be related to three aspects. First, infrequent intergenerational contact leads to loneliness in older adults, thereby resulting in increased depressive symptoms. Loneliness is a subjective and negative feeling that occurs when individuals experience diminished social relationships [55]. On the one hand, infrequent contact with family can heighten the risk for loneliness [56], because loneliness is usually conceptualized as perceived social isolation [57], and infrequent social contact is an objective measure of perceived social isolation [58]. Moreover, Chinese family culture attaches great importance to the happiness of a family union. Thus, the elderly Chinese are prone to loneliness when they are unable to receive sufficient companionship from their adult children. On the other hand, depressive symptoms were regarded as a logical consequence of loneliness [59]. Previous studies have shown that loneliness is consistently and strongly associated with depressive symptoms [60-62]. Therefore, loneliness may be an intermediate step between reduced intergenerational contact and depressive symptoms.

Second, infrequent intergenerational contact limits the availability of family support for the elderly. Social support for many elderly adults comes from family members. Specifically, intergenerational support is a primary component that may improve the psychological wellbeing of elderly parents [63]. Poulin et al. [64] argued 
that family support from adult children can prevent depressive symptoms in elderly Chinese people. Conversely, loss of support from children is a key reason for the high prevalence of depressive symptoms in this population [13]. Furthermore, part of intergenerational contact is the provision of home care, and it has been reported that the Chinese elderly who worry about the lack of caregivers tend to have higher levels of depressive symptoms [65]. Hence, decreased intergenerational contact may be related to reduced caregiving, thereby leading to increased depressive symptoms.

Third, infrequent intergenerational contact is not conducive to maintaining a good parent-child relationship. Poor relationships are associated with depressive symptoms in the elderly. Intergenerational contact is considered a critical indicator of the strength of the parent-child relationship [19]. Frequent contact provides opportunities for companionship and socialising, thus promoting the parent-child relationship. Li et al. [66] reported that parent-child relationships may directly affect depressive symptoms amongst the elderly Chinese population. In addition, a study in elderly people living in the rural areas of the U.S. similarly concluded that parent-child relationships were inversely associated with depressive symptoms [67].

Several limitations of this study should be addressed. We attempted to consider all children of survey participants who had multiple children. However, having infrequent contact with one child may matter less if other children maintain relatively more frequent contact. Also the effects of contact frequency on depressive symptoms may be different between each child. Thus, our use of the average frequency of intergenerational contact for parents with multiple children may produce bias. Investigating these potential effects is beyond the scope of our study, but it is important for future studies to investigate each parent-child relationship or factors that contribute to differences between each child. Next, we did not have study variables that described qualities stemming from intergenerational contact, such as loneliness, social support and parent-child relationships. Therefore, comprehensive and structural relationships for these variables were not obtained. Finally, the data were cross-sectional, which allowed us to analyse associations between variables, but a causal relationship between intergenerational contact and depressive symptoms could not be determined. To address these issues, future longitudinal analyses that feature additional variables should be conducted to enhance our understanding of the relationship between intergenerational contact and depressive symptoms.

\section{Conclusions}

The present study demonstrates that lower intergenerational contact frequency with children is independently associated with greater depressive symptoms amongst the elderly Chinese population. The ORs for depressive symptoms show an increasing trend with decreasing frequency of contact with children of the participants. Our results suggest that provision of depression prevention services should be considered for older Chinese people. A number of demographic characteristics are related to depressive symptoms and should be taken into account during screening. Scholars and policy makers should pay attention to family cultural norms when health interventions are considered in the elderly Chinese population.

\section{Abbreviations \\ CHARLS: China Health and Retirement Longitudinal Study; CHARLS- GIS: CHARLS-Geographic Information System; CES-D-10: The 10-item version of the Centre for Epidemiologic Studies Depression Scale; OR: Odds ratio; 95\% Cl: The 95\% confidence intervals; GDS: Geriatric Depression Scale; COVID-19: The coronavirus disease 2019}

\section{Acknowledgments}

The research team of CHARLS are acknowledged for their work.

\section{Authors' contributions}

YX conducted data analysis and is a major contributor in writing the manuscript. MM contributed in raw data processing, software application, and writing the manuscript. WW performed part of raw data processing, revised the manuscript. YPZ and YTZ revised the manuscript. XT designed and was responsible for the study. All authors read and approved the final manuscript.

\section{Funding}

None.

Availability of data and materials

The datasets analysed during the current study are available in the CHARLS repository: http://charls.pku.edu.cn/index/en.html.

\section{Ethics approval and consent to participate}

The authors assert that all procedures contributing to this work comply with the ethical standards of the relevant national and institutional committees on human experimentation and with the Helsinki Declaration of 1975, as revised in 2008.

\section{Consent for publication}

Not applicable.

\section{Competing interests}

The authors declare that they have no competing interests.

\section{Author details}

${ }^{1}$ Wuhan University, No.115 of Donghu Road, Wuhan 430000, China. ${ }^{2}$ Wuhan Blood Center, No.8 of Baofeng One Road, Wuhan 430000, China.

Received: 10 March 2020 Accepted: 1 September 2020 Published online: 15 September 2020

\section{References}

1. Blazer DG. Depression in late life: review and commentary. J Gerontol A-Biol. 2003;58:249-65.

2. World Health Organization. Depression and other common mental disorders: Global Health Estimates. Geneva: World Health Organization; 2017. p. 2.

3. Qin T, Liu W, Yin M, Shu C, Yan M, Zhang J, et al. Body mass index moderates the relationship between $C$-reactive protein and depressive symptoms: evidence from the China health and retirement longitudinal study. Sci Rep-UK. 2017;7:39940.

4. Ni Y, Tein JY, Zhang M, Yang Y, Wu G. Changes in depression among older adults in China: a latent transition analysis. J Affect Disord. 2017;209:3-9. 
5. Haigh EAP, Bogucki OE, Sigmon ST, Blazer DG. Depression among older adults: a 20-year update on five common myths and misconceptions. Am J Geriatr Psychiatry. 2018;26:107-22.

6. Liu J, Dong X, Nguyen D, Lai DWL. Family relationships and depressive symptoms among Chinese older immigrants in the United States. J Gerontol A Biol Sci Med Sci. 2017;72(Suppl 1):S113-S8.

7. Van Orden KA, Chen S, O'Riley A, Conwell Y. Course of late-life depression in China is chronic and unremitting. Int J Geriatr Psychiatry. 2015;30:409-15.

8. Ward JB, Albrecht SS, Robinson WR, Pence BW, Maselko J, Haan MN, et al. Neighborhood language isolation and depressive symptoms among elderly U.S. Latinos. Ann Epidemiol. 2018;28:774-82.

9. Kong D, Wong Yl, Dong X. Face-saving and depressive symptoms among U. S. Chinese older adults. J Immigr Minor Health. 2020.

10. Glaesmer H, Riedel-Heller S, Braehler E, Spangenberg L, Luppa M. Age- and gender-specific prevalence and risk factors for depressive symptoms in the elderly: a population-based study. Int Psychogeriatr. 2011;23:1294-300.

11. Mantzorou M, Vadikolias K, Pavlidou E, Serdari A, Vasios G, Tryfonos C, et al. Nutritional status is associated with the degree of cognitive impairment and depressive symptoms in a Greek elderly population. Nutr Neurosci. 2020;23:201-9.

12. Park MS, Hwang KG, Choi BY. Correlation between depressive symptoms and subjective mastication ability and ability to pronunciation among Korean elderly. Epidemiol Health. 2016;38:e2016035.

13. Yu J, Li J, Cuijpers P, Wu S, Wu Z. Prevalence and correlates of depressive symptoms in Chinese older adults: a population-based study. International journal of geriatric psychiatry. 2012;27:305-12.

14. Team CR. Challenges of population aging in China: Evidence from the national baseline survey of the China Health and Retirement Longitudinal Study (CHARLS); 2013. p. 6

15. Zhang C, Zhu R, Lu J, Xue Y, Hou L, Li M, et al. Health promoting lifestyles and influencing factors among empty nesters and non-empty nesters in Taiyuan, China: a cross-sectional study. Health Qual Life Out. 2018;16:103.

16. Age composition and dependence ratio of population, national data: National Bureau of Statistics of China. 2019. http://data.stats.gov.cn/english/ easyquery.htm?cn=C01. Accessed 9 Sept 2019.

17. Djundeva M, Mills $M$, Wittek $R$, Steverink N. Receiving instrumental support in late parent-child relationships and parental depression. J Gerontol B Psychol Sci Soc Sci. 2015;70:981-94.

18. Oxman TE, Berkman LF, Kasl S, Freeman DH Jr, Barrett J. Social support and depressive symptoms in the elderly. Am J Epidemiol. 1992;135:356-68.

19. Tosi M, Grundy E. Intergenerational contacts and depressive symptoms among older parents in Eastern Europe. Aging Ment Health. 2019;23:686-92.

20. Lee GR, Netzer JK, Coward RT. Depression among older parents: the role of intergenerational exchange. J Marriage Fam. 1995;57:823-33.

21. Bengtson VL, Biblarz TJ, Roberts REL. How families still matter : a longitudinal study of youth in two generations. Cambridge; New York: Cambridge University Press; 2002. p. 215. xxii.

22. Golden J, Conroy RM, Bruce I, Denihan A, Greene E, Kirby M, et al. Loneliness, social support networks, mood and wellbeing in communitydwelling elderly. Int J Geriatr Psychiatry. 2009;24:694-700.

23. Ward R, Deane G, Spitze G. Life-course changes and parent-adult child contact. Res Aging. 2014;36:568-602.

24. Buber I, Engelhardt $\mathrm{H}$. Children's impact on the mental health of their older mothers and fathers: findings from the survey of health, ageing and retirement in Europe. Eur J Ageing. 2008;5:31-45.

25. Li N, Pang L, Chen G, Song X, Zhang J, Zheng X. Risk factors for depression in older adults in Beijing. Can J Psychiatr. 2011;56:466-73.

26. Huang Q, Zhang X, Guo P, Chen G. Relationship between self-rated filial piety and depressive symptoms among the elderly. Chinese J Epidemiology. 2015;36:612-6.

27. Wu MH, Chang SM, Chou FH. Systematic literature review and metaanalysis of filial piety and depression in older people. J Transcult Nurs. 2018;29:369-78

28. Dong $X$, Li M, Hua Y. The association between filial discrepancy and depressive symptoms: findings from a community-dwelling Chinese aging population. J Gerontol A Biol Sci Med Sci. 2017;72(suppl 1):S63-S8.

29. Zhao Y, Wang Y, Chen X, Meng Q, Tang Y, Zhang T, et al. China Health and Retirement Report. China Health and Retirement Longitudinal Study; 2019.

30. Gao M, Li Y, Zhang S, Gu L, Zhang J, Li Z, et al. Does an empty nest affect elders' health? Empirical evidence from China. Int J Environ Res Public Health. 2017;14.
31. Su D, Wu XN, Zhang YX, Li HP, Wang WL, Zhang JP, et al. Depression and social support between China' rural and urban empty-nest elderly. Arch Gerontol Geriatr. 2012;55:564-9.

32. Zhang C, Hou L, Zheng X, Zhu R, Zhao H, Lu J, et al. Risk factors of mental disorders among empty and non-empty nesters in Shanxi, China: a crosssectional study. Health Qual Life Out. 2019;17(1):18.

33. Xie LQ, Zhang JP, Peng F, Jiao NN. Prevalence and related influencing factors of depressive symptoms for empty-nest elderly living in the rural area of YongZhou, China. Arch Gerontol Geriatr. 2010;50:24-9.

34. Yao $Y$, Ding $G$, Wang $L$, Jin $Y$, Lin J, Zhai $Y$, et al. Risk factors for depression in empty nesters: a cross-sectional study in a coastal city of Zhejiang Province and China. Int J Environ Res Public Health. 2019;16.

35. About CHARLS. 2018. http://charls.pku.edu.cn/en/page/about/CHARLS. Accessed 9 Sept 2019.

36. Andresen EM, Malmgren JA, Carter WB, Patrick DL. Screening for depression in well older adults: evaluation of a short form of the CES-D (Center for Epidemiologic Studies Depression Scale). Am J Prev Med. 1994;10:77-84

37. Huang QB, Wang XH, Chen G. Reliability and validity of 10-item CES-D among middle aged and older adults in China. China J Health Psychol. 2015;23:1036-41.

38. Boey KW. Cross-validation of a short form of the CES-D in Chinese elderly. Int J Geriatr Psychiatry. 1999;14(8):608-17.

39. Cao PY, Luo HQ, Hou LS, Yang XX, Ren XH. Depressive symptoms in the mid- and old-aged people in China. J Sichuan Univ Med Sci Edition. 2016; 47:763-7.

40. Chin WY, Choi EP, Wan EY. Trajectory pathways for depressive symptoms and their associated factors in a Chinese primary care cohort by growth mixture modelling. PLoS One. 2016;11:e0147775.

41. Yang Z, Chen R, Hu X, Ren XH. Factors that related to the depressive symptoms among elderly in urban and rural areas of China. Chin J Epidemiology. 2017;38:1088-93.

42. Hsiao YC, Chen CY. Exploring individual, family, and extrafamilial factors associated with depression among elderly residents of care settings. Int J Aging Hum Dev. 2018;86:219-41.

43. Tanaka H, Sasazawa Y, Suzuki S, Nakazawa M, Koyama H. Health status and lifestyle factors as predictors of depression in middle-aged and elderly Japanese adults: a seven-year follow-up of the Komo-lse cohort study. BMC Psychiatry. 2011:11:20.

44. Durrleman S, Simon R. Flexible regression models with cubic splines. Stat Med. 1989:8:551-61.

45. Govindarajulu US, Spiegelman D, Thurston SW, Ganguli B, Eisen EA. Comparing smoothing techniques in cox models for exposure-response relationships. Stat Med. 2007;26:3735-52.

46. Hidaka S, Ikejima C, Kodama C, Nose M, Yamashita F, Sasaki M, et al. Prevalence of depression and depressive symptoms among older Japanese people: comorbidity of mild cognitive impairment and depression. Int J Geriatr Psychiatry. 2012;27:271-9.

47. Conde-Sala JL, Garre-Olmo J, Calvo-Perxas L, Turro-Garriga O, VilaltaFranch J. Course of depressive symptoms and associated factors in people aged 65+ in Europe: a two-year follow-up. J Affect Disord. 2018; 245:440-50

48. Jerez-Roig J, de Oliveira NP, de Lima Filho BF, de Farias Bezerra MA, Matias $M G$, Ferreira LM, et al. Depressive symptoms and associated factors in institutionalized elderly. Exp Aging Res. 2016;42(5):479-91.

49. Simkhada R, Wasti SP, Gc VS, Lee ACK. Prevalence of depressive symptoms and its associated factors in older adults: a cross-sectional study in Kathmandu, Nepal. Aging Ment Health. 2018;22:802-7.

50. Franco-Diaz KL, Fernandez-Nino JA, Astudillo-Garcia Cl. Prevalence of depressive symptoms and factorial invariance of the Center for Epidemiologic Studies (CES-D) depression scale in a group of Mexican indigenous population. Biomedica : revista del Instituto Nacional de Salud. 2018:38:127-40.

51. Teo AR, Choi H, Andrea SB, Valenstein M, Newsom JT, Dobscha SK, et al. Does mode of contact with different types of social relationships predict depression in older adults? Evidence from a nationally representative survey. J Am Geriatr Soc. 2015;63:2014-22.

52. Brooks SK, Webster RK, Smith LE, Woodland L, Wessely S, Greenberg N, et al. The psychological impact of quarantine and how to reduce it: rapid review of the evidence. Lancet. 2020;395:912-20. 
53. Hossain MM, Sultana A, Purohit N. Mental health outcomes of quarantine and isolation for infection prevention: A systematic umbrella review of the global evidence. Epidemiol Health. 2020:e2020038.

54. Luo X, Estill J, Wang Q, Lv M, Liu Y, Liu E, et al. The psychological impact of quarantine on coronavirus disease 2019 (COVID-19). Psychiatry Res. 2020; 291:113193.

55. Singh A, Misra N. Loneliness, depression and sociability in old age. IPJ. 2009; 18:51-5.

56. Cacioppo JT, Hawkley LC, Thisted RA. Perceived social isolation makes me sad: 5-year cross-lagged analyses of loneliness and depressive symptomatology in the Chicago health, aging, and social relations study. Psychol Aging. 2010;25:453-63.

57. Cacioppo JT, Hawkley LC, Norman GJ, Berntson GG. Social isolation. Ann N Y Acad Sci. 2011;1231:17-22.

58. Coyle CE, Dugan E. Social isolation, loneliness and health among older adults. J Aging Health. 2012;24:1346-63.

59. van Beljouw IM, van Exel E, de Jong GJ, Comijs HC, Heerings M, Stek ML, et al. "being all alone makes me sad": loneliness in older adults with depressive symptoms. Int Psychogeriatr. 2014:1-11.

60. Prince MJ, Harwood RH, Blizard RA, Thomas A, Mann AH. Social support deficits, loneliness and life events as risk factors for depression in old age. The gospel oak project VI. Psychol Med. 1997;27:323-32.

61. Rashid A, Tahir I. The prevalence and predictors of severe depression among the elderly in Malaysia. J Cross Cult Gerontol. 2015;30:69-85.

62. Tiikkainen P, Heikkinen RL. Associations between loneliness, depressive symptoms and perceived togetherness in older people. Aging Ment Health. 2005;9:526-34.

63. Silverstein M, Bengtson VL. Does intergenerational social support influence the psychological well-being of older parents? The contingencies of declining health and widowhood. Soc Sci Med. 1994;38:943-57.

64. Poulin J, Deng R, Ingersoll TS, Witt H, Swain M. Perceived family and friend support and the psychological well-being of American and Chinese elderly persons. J Cross Cult Gerontol. 2012;27:305-17.

65. Xu L, Li Y, Min J, Chi I. Worry about not having a caregiver and depressive symptoms among widowed older adults in China: the role of family support. Aging Ment Health. 2017;21:879-88.

66. Li C, Jiang S, Zhang X. Intergenerational relationship, family social support, and depression among Chinese elderly: a structural equation modeling analysis. J Affect Disord. 2019;248:73-80.

67. Stimpson JP, Tyler KA, Hoyt DR. Effects of parental rejection and relationship quality on depression among older rural adults. Int J Aging Hum Dev. 2005; 61:195-210.

\section{Publisher's Note}

Springer Nature remains neutral with regard to jurisdictional claims in published maps and institutional affiliations.

Ready to submit your research? Choose BMC and benefit from:

- fast, convenient online submission

- thorough peer review by experienced researchers in your field

- rapid publication on acceptance

- support for research data, including large and complex data types

- gold Open Access which fosters wider collaboration and increased citations

- maximum visibility for your research: over $100 \mathrm{M}$ website views per year

At $\mathrm{BMC}$, research is always in progress.

Learn more biomedcentral.com/submissions 